\title{
The metabolic syndrome of $\omega 3$-depleted rats. III. Brain phospholipids
}

\author{
LAURENCE PORTOIS $^{1}$, MIRJAM HACQUEBARD ${ }^{1}$, WILLY J. MALAISSE ${ }^{2}$ and YVON A. CARPENTIER ${ }^{1}$ \\ Laboratories of ${ }^{1}$ Experimental Surgery, ${ }^{2}$ Experimental Hormonology, \\ Université Libre de Bruxelles, B-1070 Brussels, Belgium
}

Received March 19, 2009; Accepted May 20, 2009

DOI: 10.3892/ijmm_00000230

\begin{abstract}
Rats exposed from 7 weeks after birth and for the ensuing 3 to 7 months to a diet depleted in long-chain polyunsaturated $\omega 3$ fatty acids were recently proposed as a new animal model for the metabolic syndrome. The present study aimed mainly at investigating whether, in this new model, the perturbation of the fatty acid total content and pattern of brain phospholipids simulates that previously documented in second-generation $\omega 3$-depleted rats. Such was indeed the case, with the apparent exception of changes in the $\mathrm{C} 18: 1 \omega 9, \mathrm{C} 20: 0, \mathrm{C} 22: 0$ and $\mathrm{C} 24: 0$ relative content of brain phospholipids. Moreover, the $\mathrm{C} 22: 5 \omega 3$ content of such phospholipids was unexpectedly lower in the present model than in the second-generation $\omega 3$-depleted rats. The changes in brain phospholipids were also monitored when the rats deprived of $\omega 3$ fatty acids for 7 months were given access for 2 to 4-5 weeks to a flaxseed oil-enriched diet. Most phospholipid variables were rapidly normalized under the latter experimental conditions. The results obtained under these conditions suggest that an increase in the brain phospholipid C22:5 $\omega 3$ content may play a key role in the orexigenic effects of exogenous $\omega 3$ fatty acids supplied to $\omega 3$-depleted animals.
\end{abstract}

\section{Introduction}

Perturbations of the total fatty acid content and fatty acid pattern of brain phospholipids and triglycerides were recently documented in second-generation rats depleted in long-chain polyunsaturated $\omega 3$ fatty acids ( $\omega 3 \mathrm{D}$ rats) (1). The present study aims mainly at investigating the two following issues. First, it is explored whether a situation comparable to that previously documented in the second-generation $\omega 3 \mathrm{D}$ rats may be reached

Correspondence to: Professor Willy J. Malaisse, Laboratory of Experimental Hormonology, Université Libre de Bruxelles, 808 Route de Lennik, B-1070 Brussels, Belgium

E-mail:malaisse@ulb.ac.be

Key words: $\omega 3$-depleted rats, brain phospholipids, fatty acid pattern when 7-week-old normal rats are exposed to a dietary deprivation of $\omega 3$ fatty acids for only 3 to 7 months, i.e. under experimental conditions more likely to simulate the situation found in human subjects with an insufficient dietary supply of $\omega 3$ acids. Second, after 7 months of dietary $\omega 3$ deprivation, the $\omega 3 \mathrm{D}$ rats were given access for 2 to $4-5$ weeks to an $\omega 3$-rich flaxseed oil-enriched diet. The characterization of the fatty acid profile in the brain phospholipids of these animals aimed at identifying factors possibly responsible for the rapid and considerable gain in body weight and, presumably, food intake occurring under these conditions in the $\omega 3 \mathrm{D}$ rats $(2)$.

\section{Materials and methods}

The eight groups of female rats examined in this study were previously described (3). In the Tables, they are indicated as follows: $3 \mathrm{mC}$ and $7 \mathrm{mC}$ for the control animals exposed for 3 or 7 months to a soya lipid-containing diet, $3 \mathrm{mD}$ and $7 \mathrm{mD}$ for the $\omega 3 \mathrm{D}$ rats given access for 3 or 7 months to a sunflower oil-containing diet, $7 \mathrm{mC} / 4 \mathrm{wS}$ and $7 \mathrm{mC} / 4 \mathrm{wF}$ for the control rats exposed during the last 4-5 weeks to either a soybean (S) or flaxseed $(\mathrm{F})$ oil-enriched diet, and $7 \mathrm{mC} / 2 \mathrm{wF}$ and $7 \mathrm{mD} / 4 \mathrm{wF}$ for the $\omega 3 \mathrm{D}$ rats exposed for either 2 or $4-5$ weeks to a flaxseed oil-enriched diet. For the sake of comparison, one group of 18 female second-genration $\omega 3 \mathrm{D}$ rats $(2 \mathrm{gD})$ and one corresponding group of 16 female control animals $(2 \mathrm{gC})$ are also listed in the Tables. The information on brain lipids in the latter two groups of rats was already reported elsewhere (1).

The lipid composition of the diets was also detailed in a prior report (3).

At sacrifice, the brain was processed for measurement of phospholipid and triglyceride fatty acid pattern, as previously described $(1,3)$.

All results are presented as means \pm SE together with the number of individual determinations (n) or degree of freedom (df). The statistical significance of differences between mean values was assessed using the Student's t-test and confirmed by variance analysis with the Bonferroni post-test.

\section{Results}

Total fatty acid content of brain lipids. The total fatty acid content of brain phospholipids failed to differ significantly in 

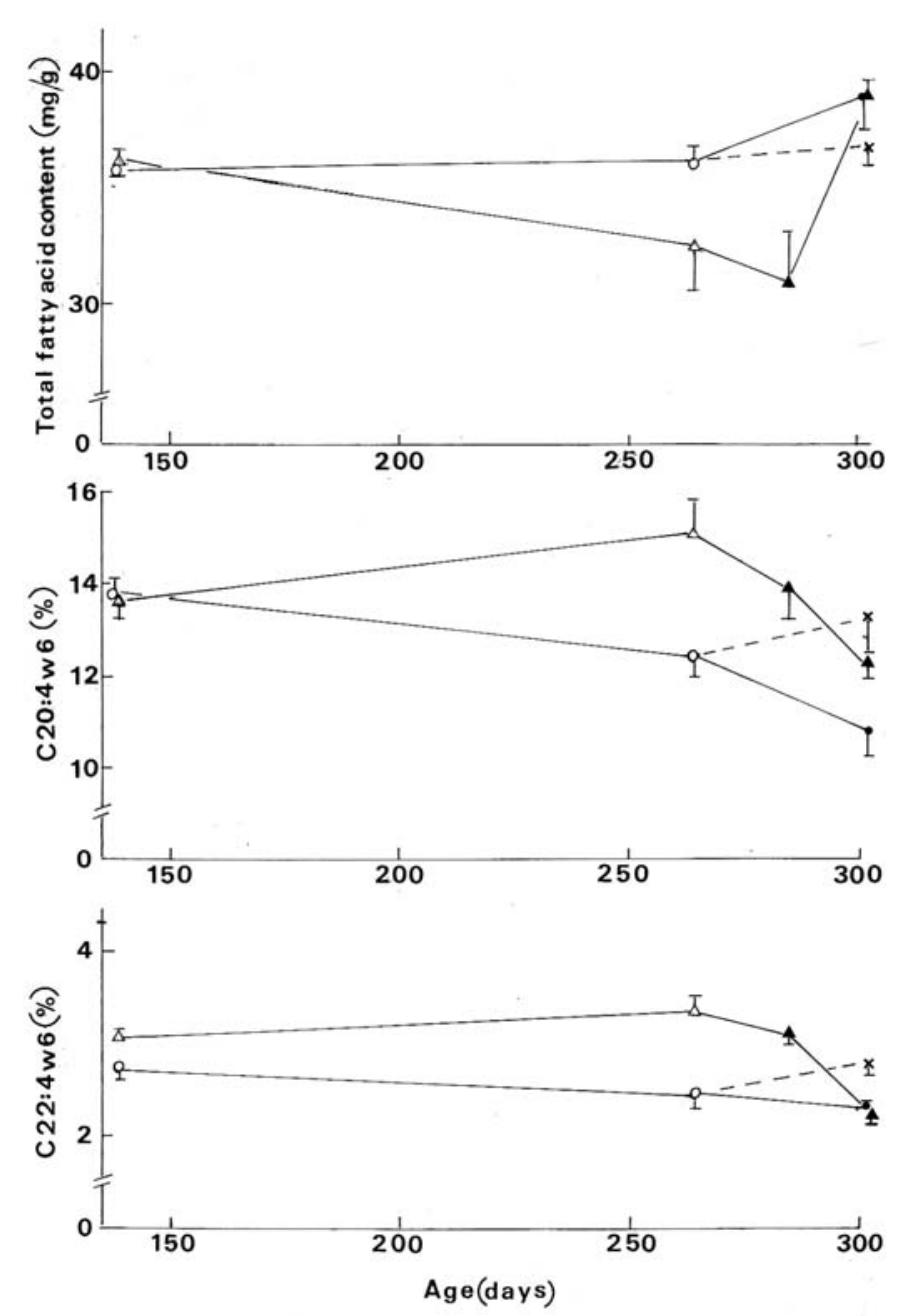

Figure 1. Time course for the changes in total fatty acid content of brain

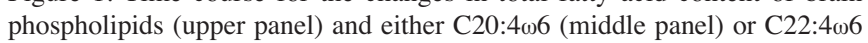
(lower panel) weight percentage in such phospholipids in control animals (circles and cross) and $\omega 3$ rats (triangles) exposed during the last 4-5 weeks to either a soybean oil-enriched diet (cross) or a flaxseed oil-enriched diet (closed symbols). Mean values $( \pm \mathrm{SE}$ ) refer to 5-6 rats at each time point.

the control animals $(35.98 \pm 0.36 \mathrm{mg} / \mathrm{g} ; \mathrm{n}=11)$ and $\omega 3 \mathrm{D}$ rats (34.41 $\pm 1.09 \mathrm{mg} / \mathrm{g} ; \mathrm{n}=12$ ) examined during the first 7 months of the present experiments, as well as in the control animals $(37.95 \pm 0.89 \mathrm{mg} / \mathrm{g} ; \mathrm{n}=12)$ and $\omega 3 \mathrm{D}$ rats $(35.07 \pm 1.64 \mathrm{mg} / \mathrm{g}$; $\mathrm{n}=12$ ) examined during the last 4-5 weeks of these experiments. At the most, there was a trend towards a lower value in $\omega 3 \mathrm{D}$ rats than in control animals. Thus, as judged from the above-mentioned values, the results recorded in the $\omega 3 \mathrm{D}$ rats averaged $94.0 \pm 2.6 \%(\mathrm{n}=24 ; \mathrm{p}<0.05)$ of the mean corresponding values found in the control animals $(100.0 \pm 1.3 \% ; n=23)$. In second-generation $\omega 3 \mathrm{D}$ rats, the total fatty acid content of brain phospholipids was even more severely decreased $(\mathrm{p}<0.02)$, the results recorded in these rats averaging no more than $82.9 \pm 2.0 \%(n=18 ; \mathrm{p}<0.001)$ of the mean value found in the corresponding control animals $(100.0 \pm 3.2 \% ; n=16)$. As illustrated in Fig. 1, when either the control animals or $\omega 3 \mathrm{D}$ rats were exposed for the last 4-5 weeks before sacrifice to a flaxseed oil-enriched diet, the mean values for the total fatty acid content of brain phospholipids increased above the level reached after the first 7 months

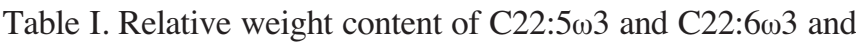
$\mathrm{C} 22: 5 \omega 3 / \mathrm{C} 22: 6 \omega 3$ ratio in brain phospholipids.

\begin{tabular}{lccc}
\hline Rat & $\begin{array}{c}\mathrm{C} 22: 5 \omega 3 \\
(\%)\end{array}$ & $\begin{array}{c}\mathrm{C} 22: 6 \omega 3 \\
(\%)\end{array}$ & $\begin{array}{c}\mathrm{C} 22: 5 \omega 3 / \mathrm{C} 22: 6 \omega 3 \\
(\% \circ)\end{array}$ \\
\hline $3 \mathrm{mC}$ & $2.10 \pm 0.07(6)$ & $25.3 \pm 0.6(6)$ & $8.31 \pm 0.37(6)$ \\
$3 \mathrm{mD}$ & $0.46 \pm 0.10(6)$ & $20.3 \pm 0.6(6)$ & $2.19 \pm 0.46(6)$ \\
$7 \mathrm{mC}$ & $2.24 \pm 0.15(5)$ & $24.1 \pm 1.0(5)$ & $9.41 \pm 0.93(5)$ \\
$7 \mathrm{mD}$ & $0.00 \pm 0.00(6)$ & $16.8 \pm 0.5(6)$ & $0.00 \pm 0.00(6)$ \\
$7 \mathrm{mC} / 4 \mathrm{wS}$ & $2.35 \pm 0.12(6)$ & $22.7 \pm 0.6(6)$ & $10.37 \pm 0.51(6)$ \\
$7 \mathrm{mC} / 4 \mathrm{wF}$ & $3.70 \pm 0.16(6)$ & $21.9 \pm 1.1(6)$ & $17.05 \pm 1.03(6)$ \\
$7 \mathrm{mD} / 2 \mathrm{wF}$ & $3.37 \pm 0.22(6)$ & $19.2 \pm 0.4(6)$ & $17.57 \pm 1.09(6)$ \\
$7 \mathrm{mD} / 4 \mathrm{wF}$ & $4.04 \pm 0.38(6)$ & $20.3 \pm 0.6(6)$ & $19.75 \pm 1.41(6)$ \\
$2 \mathrm{gC}$ & $2.74 \pm 0.10(16)$ & $23.7 \pm 0.9(16)$ & $12.01 \pm 0.79(16)$ \\
$2 \mathrm{gD}$ & $0.39 \pm 0.08(18)$ & $4.6 \pm 0.2(18)$ & $8.29 \pm 1.90(18)$ \\
\hline
\end{tabular}

of the present experiments; such an increase, however, only achieved statistical significance $(\mathrm{p}<0.01)$ in the $\omega 3 \mathrm{D}$ rats.

The total fatty acid content of brain triglycerides did not differ significantly $(\mathrm{df}=32 ; \mathrm{p}>0.2)$ in control animals and second-generation $\omega 3 \mathrm{D}$ rats $(1)$. Likewise, during the first 7 months of the present experiments and after a further period of 4-5 weeks exposure to a flaxseed oil-enriched diet, such a content averaged in the $\omega 3 \mathrm{D}$ rats $99.0 \pm 10.4 \%(\mathrm{n}=18 ; \mathrm{p}>0.95)$ of the mean corresponding value(s) found at the same age in control animals $(100.0 \pm 15.6 \% ; n=17)$.

Long-chain polyunsaturated $\omega 3$ fatty acid content of brain

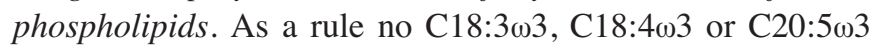
was detected in brain phospholipids.

The relative $\mathrm{C} 22: 5 \omega 3$ weight content of brain phospholipids was much lower $(\mathrm{p}<0.001)$ in $\omega 3 \mathrm{D}$ rats than in control animals (Table I). In the former rats, it decreased from $0.46 \pm 0.10 \%$ o $(n=6)$ to undetectable values after respectively 3 and 7 months exposure to the $\omega 3$-depleted diet. When the $\omega 3 \mathrm{D}$ rats were exposed for 2 to 4-5 weeks to the flaxseed oil-enriched diet, the relative weight content of $\mathrm{C} 22: 5 \omega 3$ increased to $3.70 \pm 0.23 \%$ o $(n=12)$, a value significantly higher $(\mathrm{p}<0.001)$ than that otherwise recorded in the control animals examined during the first 7 months of the present experiments $(2.16 \pm 0.08 \% ; n=11)$. Even in the control animals, the relative weight content of $\mathrm{C} 22: 5 \mathrm{w} 3$ in brain phospholipids was increased $(\mathrm{p}<0.001)$, relative to the value found 7 months after the onset of the present experiments, when these animals were exposed to the flaxseed oil-enriched diet, whilst such was not the case $(p>0.5)$ after exposure to the soybean oilenriched diet. The values recorded after 4-5 weeks exposure to the flaxseed oil-enriched diets failed to differ significantly ( $p>0.4)$ in control animals and $\omega 3 \mathrm{D}$ rats. In the secondgeneration $\omega 3 \mathrm{D}$ rats, the weight percentage of $\mathrm{C} 22: 5 \omega 3$ in brain phospholipids was, unexpectedly, higher $(\mathrm{p}<0.02)$ than that recorded in the $\omega 3 \mathrm{D}$ rats examined at the 7 th month of the present experiments.

A somewhat different situation prevailed in the case of $\mathrm{C} 22: 6 \omega 3$. First, the relative weight content of $\mathrm{C} 22: 6 \omega 3$ in brain 
Table II. Relative weight content of long-chain polyunsaturated $\omega 6$ fatty acids in brain phospholipids.

\begin{tabular}{llllll}
\hline Rats & $\mathrm{C} 18: 2 \omega 6(\%)$ & $\mathrm{C} 20: 2 \omega 6(\%)$ & $\mathrm{C} 20: 3 \omega 6(\%)$ & $\mathrm{C} 20: 4 \omega 6(\%)$ & $\mathrm{C} 22: 4 \omega 6(\%)$ \\
\hline $3 \mathrm{mC}$ & $7.38 \pm 0.31(6)$ & $1.17 \pm 0.03(6)$ & $2.16 \pm 0.11(6)$ & $13.77 \pm 0.33(6)$ & $2.72 \pm 0.10(6)$ \\
$3 \mathrm{mD}$ & $6.60 \pm 0.23(6)$ & $1.37 \pm 0.07(6)$ & $1.81 \pm 0.11(6)$ & $13.62 \pm 0.37(6)$ & $3.08 \pm 0.09(6)$ \\
$7 \mathrm{mC}$ & $8.00 \pm 0.26(5)$ & $1.34 \pm 0.04(5)$ & $2.54 \pm 0.22(5)$ & $12.42 \pm 0.48(5)$ & $2.46 \pm 0.16(5)$ \\
$7 \mathrm{mD}$ & $6.22 \pm 0.43(6)$ & $1.30 \pm 0.10(6)$ & $1.37 \pm 0.12(6)$ & $15.10 \pm 0.72(6)$ & $3.37 \pm 0.12(6)$ \\
$7 \mathrm{mC} / 4 \mathrm{wS}$ & $9.30 \pm 0.58(6)$ & $1.33 \pm 0.10(6)$ & $3.73 \pm 0.08(6)$ & $13.28 \pm 0.78(6)$ & $2.78 \pm 0.13(6)$ \\
$7 \mathrm{mC} / 4 \mathrm{wF}$ & $9.66 \pm 0.70(6)$ & $1.46 \pm 0.07(6)$ & $3.82 \pm 0.08(6)$ & $10.80 \pm 0.55(6)$ & $2.25 \pm 0.13(6)$ \\
$7 \mathrm{mD} / 2 \mathrm{wF}$ & $7.39 \pm 0.44(6)$ & $1.35 \pm 0.07(6)$ & $2.46 \pm 0.10(6)$ & $13.92 \pm 0.72(6)$ & $3.15 \pm 0.17(6)$ \\
$7 \mathrm{mD} / 4 \mathrm{wF}$ & $8.60 \pm 0.44(6)$ & $1.70 \pm 0.17(6)$ & $2.18 \pm 0.23(6)$ & $12.23 \pm 0.27(6)$ & $2.73 \pm 0.11(6)$ \\
$2 \mathrm{gC}$ & $7.22 \pm 0.21(16)$ & $1.73 \pm 0.08(16)$ & $3.40 \pm 0.16(16)$ & $12.04 \pm 0.30(16)$ & $2.87 \pm 0.07(16)$ \\
$2 \mathrm{gD}$ & $7.50 \pm 0.72(18)$ & $1.78 \pm 0.05(18)$ & $2.91 \pm 0.10(18)$ & $18.00 \pm 0.30(18)$ & $4.43 \pm 0.07(18)$ \\
\hline & & & & &
\end{tabular}

phospholipids decreased $(\mathrm{p}<0.005)$ in the $\omega 3 \mathrm{D}$ rats from $20.3 \pm 0.6 \%(n=6)$ to $16.8 \pm 0.5 \%(n=6)$ after respectively 3 and 7 months exposure to the $\omega 3$-deficient diet, these two mean values being much lower $(\mathrm{p}<0.001)$ than those recorded in the control animals of the same age but remaining much higher $(\mathrm{p}<0.001)$ than that previously recorded in second-generation $\omega 3 \mathrm{D}$ rats (Table I). Second, when the control rats were exposed for 4-5 weeks to either the soybean or flaxseed oil-enriched diet, no significant change in the $\mathrm{C} 22: 6 \mathrm{\omega} 3$ relative weight content of brain phospholipids was observed. Last, when the $\omega 3 \mathrm{D}$ rats were given access to the flaxseed oil-enriched diet, the relative weight content of $\mathrm{C} 22: 6 \omega 3$ in brain phospholipids $(19.7 \pm 0.4 \% ; n=12)$ remained lower $(\mathrm{p}<0.001)$ than that otherwise recorded in control animals $(24.8 \pm 0.5 \%$; $n=11)$, despite the fact that such a percentage was already significantly higher $(\mathrm{p}<0.005)$ in the $\omega 3 \mathrm{D}$ rats exposed for only 2 weeks to the $\omega 3$-enriched diet $(19.2 \pm 0.4 \% ; n=6)$ than in the $\omega 3 \mathrm{D}$ rats examined after 7 months exposure to the $\omega 3$-deficient diet $(16.8 \pm 0.5 \% ; \mathrm{n}=6)$.

The C22:5 $13 / \mathrm{C} 22: 6 \omega 3$ ratio was already significantly lower $(\mathrm{p}<0.001)$ in $\omega 3 \mathrm{D}$ rats than in control animals after only 3 months exposure to their respective diet. In the control animals, it failed to change significantly after 4 weeks of exposure to the soybean oil-enriched diet, whilst almost doubling $(\mathrm{p}<0.001)$ after 4 weeks of exposure to the flaxseed oil-enriched diet. The latter diet also provoked a rapid and dramatic increase of the $\mathrm{C} 22: 5 \omega 3 / \mathrm{C} 22: 6 \omega 3$ ratio in $\omega 3 \mathrm{D}$ rats. In the second-generation $\omega 3 \mathrm{D}$ rats, however, such a ratio failed to differ significantly $(\mathrm{p}>0.09)$ from that found in the corresponding control animals.

Long-chain polyunsaturated $\omega 6$ fatty acid content of brain phospholipids. Small amounts of C18:3w6 were only on occasion detected in brain phospholipids, not exceeding $0.56 \pm 0.04 \%$ o $(n=10)$ in the present experiments and $0.43 \pm 0.05 \%$ o $(n=11)$ in our prior study conducted in secondgeneration $\omega 3 \mathrm{D}$ rats and their corresponding control animals.

The relative weight content of C18:2 $\omega 6$ in brain phospholipids was lower $(\mathrm{p}<0.001)$ in $\omega 3 \mathrm{D}$ rats $(6.41 \pm 0.24 \%$; $\mathrm{n}=12)$ than in control animals $(7.66 \pm 0.22 \%$; $n=11)$. It increased $(\mathrm{p}<0.005)$ to $7.99 \pm 0.35 \%$ o $(n=12)$ when the $\omega 3 \mathrm{D}$ rats were given access to the $\omega 3$-rich diet, such a mean value failing to differ significantly $(\mathrm{p}>0.4)$ from that otherwise recorded in the control animals. These two changes represented timerelated events (Table II). Thus, the difference between control and $\omega 3 \mathrm{D}$ rats failed to achieve statistical significance $(\mathrm{p}<0.08)$ after only 3 months of exposure to their respective diet, whilst being highly significant $(\mathrm{p}<0.01)$ after 7 months of exposure to their respective diet. Likewise, the mean value recorded in the $\omega 3 \mathrm{D}$ rats after a 2 -week exposure to the $\omega 3$ enriched diet failed to differ significantly $(p<0.09)$ from that recorded in the $\omega 3 \mathrm{D}$ rats 7 months after the onset of the present experiments, whilst it became significantly different from the latter value $(\mathrm{p}<0.005)$ after $4-5$ weeks of exposure to the $\omega 3$-enriched diet. In the control rats given access for 4-5 weeks to either the soybean or flaxseed oil-enriched diet, the relative weight content of C18:2 $\omega 6$ was also higher $(\mathrm{p}<0.005)$ than that recorded in the control rats during the first 7 months of the present experiments. In the secondgeneration $\omega 3 \mathrm{D}$ rats, the $\mathrm{C} 18: 2 \omega 6$ relative content of brain phospholipids failed to differ significantly $(\mathrm{p}>0.7)$ from that found in the corresponding control animals.

The relative weight content of $\mathrm{C} 20: 2 \omega 6$ in brain phospholipids averaged $1.25 \pm 0.04 \%$ o $(n=11), 1.33 \pm 0.06 \%$ o $(n=12)$ and $1.52 \pm 0.10 \%(n=12)$, respectively, in the control and $\omega 3 \mathrm{D}$ rats (both examined during the first 7 months of the present experiments) and in the $\omega 3 \mathrm{D}$ rats given access to the $\omega 3$ enriched diet. Only the lowest and highest of these 3 mean values differed significantly $(\mathrm{p}<0.025)$ from one another. The sole other significant difference $(\mathrm{p}<0.05)$ consisted in modest increase of the $\mathrm{C} 20: 2 \omega 6$ relative content in the $\omega 3 \mathrm{D}$ rats, as compared to control animals, when examined after a 3-month exposure to their respective diet.

The C20:3 $\omega 6$ relative contribution to brain phospholipids represented in the $\omega 3 \mathrm{D}$ rats examined 3 and 7 months after onset of the present experiments $84.0 \pm 7.2 \%(\mathrm{df}=10 ; \mathrm{p}<0.06)$ and $54.1 \pm 9.3 \%(\mathrm{df}=9 ; \mathrm{p}<0.001)$ of the corresponding values found at the same age in control animals. In the control animals, exposure to either the soybean or flaxseed oilenriched diet increased $(\mathrm{p}<0.001)$ such a relative contribution. Likewise, in the $\omega 3 \mathrm{D}$ rats, exposure to the flaxseed oilenriched diet increased $(\mathrm{p}<0.001)$ the $\mathrm{C} 20: 3 \omega 6$ relative amount in brain phospholipids from $1.59 \pm 0.10 \%$ o to $2.32 \pm 0.13 \%$ o ( $n=12$ in both cases). Nevertheless, the measurements made in 
Table III. Paired ratio between selected long-chain polyunsaturated $\omega 6$ fatty acids in brain phospholipids.

\begin{tabular}{lcccc}
\hline Rats & $\mathrm{C} 20: 2 \omega 6 / \mathrm{C} 18: 2 \omega 6\left(10^{-3}\right)$ & $\mathrm{C} 20: 3 \omega 6 / \mathrm{C} 18: 2 \omega 6\left(10^{-3}\right)$ & $\mathrm{C} 20: 4 \omega 6 / \mathrm{C} 20: 3 \omega 6$ & $\mathrm{C} 22: 4 \omega 6 / \mathrm{C} 20: 4 \omega 6\left(10^{-1}\right)$ \\
\hline $3 \mathrm{mC}$ & $159.7 \pm 5.0(6)$ & $296.2 \pm 23.8(6)$ & $64.4 \pm 2.4(6)$ & $1.96 \pm 0.04(6)$ \\
$3 \mathrm{mD}$ & $209.0 \pm 12.2(6)$ & $276.0 \pm 18.8(6)$ & $77.0 \pm 6.2(6)$ & $2.26 \pm 0.05(6)$ \\
$7 \mathrm{mC}$ & $167.6 \pm 6.1(5)$ & $318.6 \pm 29.8(5)$ & $50.6 \pm 5.2(5)$ & $1.99 \pm 0.09(5)$ \\
$7 \mathrm{mD}$ & $208.4 \pm 7.0(6)$ & $219.7 \pm 7.5(6)$ & $116.3 \pm 15.7(6)$ & $2.24 \pm 0.10(6)$ \\
$7 \mathrm{mC} / 4 \mathrm{wS}$ & $142.9 \pm 2.5(6)$ & $410.4 \pm 31.6(6)$ & $35.6 \pm 2.0(6)$ & $2.10 \pm 0.05(6)$ \\
$7 \mathrm{mC} / 4 \mathrm{wF}$ & $153.3 \pm 9.6(6)$ & $403.9 \pm 23.3(6)$ & $28.4 \pm 2.0(6)$ & $2.11 \pm 0.17(6)$ \\
$7 \mathrm{mD} / 2 \mathrm{wF}$ & $183.5 \pm 7.2(6)$ & $337.1 \pm 22.2(6)$ & $57.5 \pm 5.2(6)$ & $2.26 \pm 0.08(6)$ \\
$7 \mathrm{mD} / 4 \mathrm{wF}$ & $202.2 \pm 26.3(6)$ & $257.4 \pm 31.7(6)$ & $62.1 \pm 11.6(6)$ & $2.22 \pm 0.10(6)$ \\
$2 \mathrm{gC}$ & $240.9 \pm 10.9(16)$ & $471.6 \pm 20.0(16)$ & $36.9 \pm 2.2(16)$ & $2.41 \pm 0.10(16)$ \\
$2 \mathrm{gD}$ & $216.9 \pm 8.1(16)$ & $360.1 \pm 20.8(16)$ & $63.5 \pm 8.9(18)$ & $2.47 \pm 0.04(18)$ \\
\hline
\end{tabular}

the $\omega 3 \mathrm{D}$ rats given access for $4-5$ weeks to the flaxseed oilenriched diet remained lower $(\mathrm{p}<0.001)$ than those recorded in the control rats also given access for 4-5 weeks to a flaxseed oil-enriched diet. In the second-generation $\omega 3 \mathrm{D}$ rats, the C20:3 $\omega 6$ relative amount in brain phospholipids was also lower $(\mathrm{p}<0.02)$ than in the corresponding control animals.

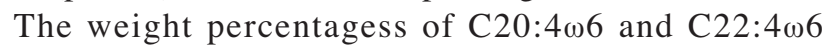
underwent comparable changes. They progressively increased in the $\omega 3 \mathrm{D}$ rats during the first 7 months of the present experiments, eventually reaching values higher $(\mathrm{p}<0.02$ or less) than those recorded in the control rats, and progressively decreased $(\mathrm{p}<0.005)$ when the $\omega 3 \mathrm{D}$ rats were exposed to the flaxseed oil-enriched diet. They were lower $(\mathrm{p}<0.05$ or less) in the control rats exposed to the flaxseed oil-enriched diet, as compared to the soybean oil-enriched diet.

The ratio between selected long-chain polyunsaturated $\omega 6$ fatty acid was also computed in the several groups of rats (Table III).

The $C 20: 2 \omega 6 / C 18: 2 \omega 6$ ratio was higher $(p<0.005)$ in the $\omega 3 \mathrm{D}$ rats than in the control animals whether 3 or 7 months after the start of the present experiments. It failed to be significantly affected when either the control rats or $\omega 3 \mathrm{D}$ rats were exposed to an oil-enriched diet, the mean value found in the $\omega 3 \mathrm{D}$ rats remaining higher $(\mathrm{p}<0.005)$ than that recorded in the control animals. The mean value for the C20:2 $06 /$ C18:2 $\omega 6$ ratio was lower in second-generation $\omega 3 \mathrm{D}$ rats than in the corresponding control animals, but such a difference failed to achieve statistical significance.

Inversely, the $C 20: 3 \omega 6 / C 18: 2 \omega 6$ ratio progressively decreased in the $\omega 3 \mathrm{D}$ rats during the first 7 months of the experiments, a significant difference $(p<0.01)$ between control animals and $\omega 3 \mathrm{D}$ rats being reached at the end of this period. Exposure of the control animals to either the soybean or flaxseed oil-enriched diet increased $(\mathrm{p}<0.001)$ the $\mathrm{C} 20: 3 \omega 6 /$ C18:2w6 ratio from a mean prior value of $306.4 \pm 18.1 \%$ o $(n=11)$ to a later mean value of $407.2 \pm 18.7 \%$ o $(n=12)$. In the $\omega 3 \mathrm{D}$ rats given access to the flaxseed oil-enriched diet for 2 to $4-5$ weeks, the $\mathrm{C} 20: 3 \omega 6 / \mathrm{C} 18: 2 \omega 6$ ratio averaged $297.9 \pm 22.0 \%$ o $(n=12)$, a value close $(p>0.7)$ to that otherwise recorded in the control animals during the first 7 months of the present experiments $(306.4 \pm 18.1 \%$; $n=11)$. In the second-generation $\omega 3 \mathrm{D}$ rats, the $\mathrm{C} 20: 3 \omega 6 / \mathrm{C} 18: 2 \omega 6$ ratio was also lower $(\mathrm{p}<0.001)$ than in the corresponding control animals.

The C20:4 $\omega 6 / C 20: 3 \omega 6$ ratio progressively increased in the $\omega 3 \mathrm{D}$ rats, becoming eventually twice higher $(\mathrm{p}<0.01)$ than that found at the same age in the control animals. A comparable situation $(\mathrm{p}<0.001)$ prevailed in the secondgeneration $\omega 3 \mathrm{D}$ rats, as compared to the corresponding control animals $(\mathrm{p}<0.001)$. When the control animals or $\omega 3 \mathrm{D}$ rats were

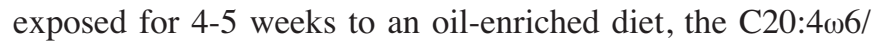
$\mathrm{C} 20: 3 \omega 6$ ratio decreased ( $\mathrm{p}<0.02$ or less) below the prior values. After 4-5 weeks of exposure to the flaxseed oilenriched diet, such a ratio remained higher $(\mathrm{p}<0.02)$, however, in $\omega 3 \mathrm{D}$ rats than in control animals.

During the first 7 months of the present experiments, the $\mathrm{C} 22: 4 \omega 6 / \mathrm{C} 20: 4 \omega 6$ ratio was higher $(\mathrm{p}<0.001)$ in $\omega 3 \mathrm{D}$ rats $(22.5 \pm 0.5 \% ; n=12)$ than in control animals $(19.8 \pm 0.4 \% ; n=11)$. No further significant changes of such a ratio was observed during the last 4-5 weeks. Nevertheless, after exposure to a flaxseed oil-enriched diet, the mean values reached in $\omega 3 \mathrm{D}$ rats was no more significantly higher $(p>0.5)$ than that found in control animals.

A last finding merits to be underlined. The results so far presented do not refer to the $\mathrm{C} 22: 5 \omega 6$ content of brain phospholipids, because it had not been measured in our usual procedure. It should not be ignored, however, that such a content was close to the limit of detection in control rats, whilst being far-from-negligible in $\omega 3 \mathrm{D}$ rats. For instance, after 3 and 7 months of dietary $\omega 3$ deprivation, it averaged, respectively, $1.26 \pm 0.08$ and $1.68 \pm 0.10 \mathrm{mg} / \mathrm{g}$ wet weight $(\mathrm{n}=6$ in both cases), the latter mean values exceeding $(\mathrm{p}<0.01)$ the former one. Likewise, the relative weight content of $\mathrm{C} 22: 5 \omega 6$ in brain phospholipids increased $(\mathrm{p}<0.001)$ from $3.4 \pm 0.2$ to $5.0 \pm 0.3 \%$ ( $n=6$ in both cases) after 3 and 7 months dietary $\omega 3$ deprivation. Over the same period, the C22:5 $\omega 6 / \mathrm{C} 22: 4 \omega 6$ ratio also increased $(\mathrm{p}<0.005)$ from $1.13 \pm 0.07$ to $1.56 \pm 0.09$ ( $n=6$ in both cases).

Saturated and monodesaturated fatty acids. A minor amount of $\mathrm{C} 12: 0(0.7 \%$ ) in brain phospholipids was only detected in one control rats among the 81 rats considered in this report.

In the second-generation $\omega 3 \mathrm{D}$ rats, the relative weight contents of brain phospholipids in C14:0 ( $<<0.001), \mathrm{C} 16: 0$ 
Table IV. Relative weight content of saturated and monodesaturated fatty acids in brain phospholipids.

\begin{tabular}{|c|c|c|c|c|}
\hline Rats & C14:0 (\%o) & C16:0 (\%) & C16:17 (\%o) & C18:0 (\%) \\
\hline $3 \mathrm{mC}$ & $0.76 \pm 0.05(6)$ & $22.43 \pm 0.21(6)$ & $3.42 \pm 0.14(6)$ & $18.62 \pm 0.12(6)$ \\
\hline $3 \mathrm{mD}$ & $1.02 \pm 0.15(6)$ & $22.10 \pm 0.40(6)$ & $3.54 \mathrm{v} 0.08(6)$ & $19.57 \pm 0.14(6)$ \\
\hline $7 \mathrm{mC}$ & $1.31 \pm 0.17(5)$ & $21.22 \pm 0.45(5)$ & $3.57 \pm 0.08(5)$ & $18.12 \pm 0.08$ \\
\hline $7 \mathrm{mD}$ & $1.42 \pm 0.04(6)$ & $23.38 \pm 0.56(6)$ & $3.66 \pm 0.12(6)$ & $19.78 \pm 0.25(6)$ \\
\hline $7 \mathrm{mC} / 4 \mathrm{wS}$ & $1.56 \pm 0.04(6)$ & $21.13 \pm 0.41(6)$ & $3.38 \pm 0.11(6)$ & $18.58 \pm 0.20(6)$ \\
\hline $7 \mathrm{mC} / 4 \mathrm{wF}$ & $1.56 \pm 0.10(6)$ & $20.48 \pm 0.68(6)$ & $3.79 \pm 0.08(6)$ & $18.57 \pm 0.16(6)$ \\
\hline $7 \mathrm{mD} / 2 \mathrm{wF}$ & $1.35 \pm 0.16(6)$ & $22.18 \pm 0.47(6)$ & $3.68 \pm 0.18(6)$ & $19.00 \pm 0.25(6)$ \\
\hline $7 \mathrm{mD} / 4 \mathrm{wF}$ & $1.30 \pm 0.14(6)$ & $21.17 \pm 0.47(6)$ & $3.78 \pm 0.18(6)$ & $19.22 \pm 0.26(6)$ \\
\hline $2 \mathrm{gC}$ & $0.92 \pm 0.02(16)$ & $20.58 \pm 0.38$ & $2.78 \pm 0.05(16)$ & $18.41 \pm 0.22(16)$ \\
\hline \multirow[t]{2}{*}{$2 \mathrm{gD}$} & $1.26 \pm 0.06(18)$ & $27.63 \pm 0.54(18)$ & $3.88 \pm 0.08$ (18) & $24.13 \pm 0.26(18)$ \\
\hline & 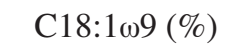 & C20:0 (\%o) & $\mathrm{C} 22: 0(\%)$ & C24:0 (\%o) \\
\hline $3 \mathrm{mC}$ & $13.62 \pm 0.48(6)$ & $2.50 \pm 0.21(6)$ & $2.04 \pm 0.29(6)$ & $4.72 \pm 0.66(6)$ \\
\hline $3 \mathrm{mD}$ & $16.72 \pm 0.58(6)$ & $3.95 \pm 0.46(6)$ & $4.12 \pm 0.56(6)$ & $9.17 \pm 1.15(6)$ \\
\hline $7 \mathrm{mC}$ & $16.76 \pm 1.01(5)$ & $3.30 \pm 0.23(5)$ & $3.45 \pm 0.38$ & $8.27 \pm 1.21(5)$ \\
\hline $7 \mathrm{mD}$ & $17.07 \pm 1.16(6)$ & $3.96 \pm 0.48(6)$ & $4.00 \pm 0.72(6)$ & $9.15 \pm 1.75(6)$ \\
\hline 7mC/4wS & $16.22 \pm 1.02(6)$ & $4.09 \pm 0.52(6)$ & $3.80 \pm 0.78$ (6) & $7.89 \pm 1.43$ (6) \\
\hline $7 \mathrm{mC} / 4 \mathrm{wF}$ & $19.62 \pm 1.36(6)$ & $4.54 \pm 0.54(6)$ & $4.81 \pm 0.54(6)$ & $10.53 \pm 1.35(6)$ \\
\hline $7 \mathrm{mD} / 2 \mathrm{wF}$ & $17.27 \pm 0.80(6)$ & $4.32 \pm 0.43(6)$ & $4.17 \pm 0.52(6)$ & $9.19 \pm 1.22(6)$ \\
\hline $7 \mathrm{mD} / 4 \mathrm{wF}$ & $18.45 \pm 0.83(6)$ & $4.32 \pm 0.39(6)$ & $4.67 \pm 0.49(6)$ & $10.73 \pm 1.15(6)$ \\
\hline $2 \mathrm{gC}$ & $17.29 \pm 0.70(16)$ & $3.95 \pm 0.35$ (16) & $4.20 \pm 0.45(16)$ & $9.49 \pm 0.79$ (16) \\
\hline $2 \mathrm{gD}$ & $16.79 \pm 0.45(18)$ & $3.13 \pm 0.18(18)$ & $3.82 \pm 0.35(18)$ & $8.20 \pm 0.72(18)$ \\
\hline
\end{tabular}

$(\mathrm{p}<0.001), \mathrm{C} 16: 1 \omega 7(\mathrm{p}<0.001)$ and $\mathrm{C} 18: 0(\mathrm{p}<0.001)$ were higher than in the corresponding control animals. The mean values for that of $\mathrm{C} 18: 1 \omega 9, \mathrm{C} 20: 0, \mathrm{C} 22: 0$ and $\mathrm{C} 24: 0$ were lower, however, in second-generation $\omega 3 \mathrm{D}$ rats than in the corresponding control animals, the latter difference only achieving statistical significance in the case of C20:0 ( $<<0.05)$.

In the present study, a comparable situation was only observed for C16:0 and C18:0. Thus, in the case of C16:0, a higher relative weight content in $\omega 3 \mathrm{D}$ rats than in control animals was observed after 7 months of dietary $\omega 3$ deprivation $(\mathrm{p}<0.02)$, but not yet after only 3 months of $\omega 3$ deprivation ( $>0.4)$. In the case of C18:0, a higher relative weight content $(p<0.001)$ in $\omega 3 \mathrm{D}$ rats was observed after both 3 and 7 months of $\omega 3$ deprivation. In the $\omega 3 \mathrm{D}$ rats, the $\mathrm{C} 16: 0$ relative weight content progressively decreased $(\mathrm{p}<0.02)$ from $23.4 \pm 0.6 \%$ to $22.2 \pm 0.5 \%$ and $21.2 \pm 0.5 \%$ ( $n=6$ in all cases) after 2 and $4-5$ weeks of exposure to the flaxseed oil-enriched diet, the last of these 3 mean values being no more different $(p>0.4)$ from that recorded in the control animals also exposed for 4-5 weeks to the flaxseed oil-enriched diet. Likewise, in the $\omega 3 \mathrm{D}$ rats exposed for 2 to $4-5$ weeks to the flaxseed oil-enriched diet, the C18:0 relative weight content $(19.1 \pm 0.2 \% ; n=12)$ was lower $(\mathrm{p}<0.025)$ than that recorded in the $\omega 3 \mathrm{D}$ rats during the first 7 months of the present experiments $(19.7 \pm 0.1 \% ; n=12)$. However, after $4-5$ weeks of exposure to the flaxseed oil-enriched diet, the mean C18:0 relative content of brain phospholipids in the $\omega 3 \mathrm{D}$ rats $(19.2 \pm 0.3 \% ; n=6)$ remained somewhat higher $(\mathrm{p}<0.07)$ than in the control animals also exposed to the flaxseed oil-enriched diet for the same period $(18.6 \pm 0.2 \% ; n=6)$. In the cases of both $\mathrm{C} 16: 0$ and C18:0, no significant difference was found in the control rats between the values recorded before and after exposure to either the soybean or flaxseed oil-enriched diet, the latter two mean values also failing to differ significantly from one another (Table IV).

There was also some analogy between the secondgeneration $\omega 3 \mathrm{D}$ rats and the present $\omega 3 \mathrm{D}$ rats in the case of C14:0. Indeed, the brain phospholipid C14:0 content averaged in the present $\omega 3 \mathrm{D}$ rats $121.7 \pm 10.2 \%(n=12)$ of the mean control values recorded at the same age in control animals $(100.0 \pm 6.4 \% ; n=11)$. Likewise, the mean value found in the $\omega 3 \mathrm{D}$ rats before exposure to the flaxseed oil-enriched diet was somewhat higher than that recorded thereafter. When these two sets of results were pooled together, the C14:0 content of $\omega 3$-deprived rats averaged $116.9 \pm 7.0 \% \quad(n=18$; $\mathrm{p}<0.05$ ) of the main corresponding reference values found in either control animals or $\omega 3 \mathrm{D}$ rats exposed to the flaxseed oil-enriched diet $(100.0 \pm 4.9 \%$; $n=23)$. In the control animals, however, the $\mathrm{C} 14: 0$ relative content of brain phospholipids was virtually identical $(p>0.95)$ in the animals exposed to either the soybean or flaxseed oil-enriched diet, largely exceeding $(\mathrm{p}<0.001)$ that recorded in the control animals during the first 7 months of the present experiments.

The results obtained with the other saturated and monodesaturated fatty acids differed in the present $\omega 3 \mathrm{D}$ rats and formerly examined second-generation $\omega 3 \mathrm{D}$ rats. 


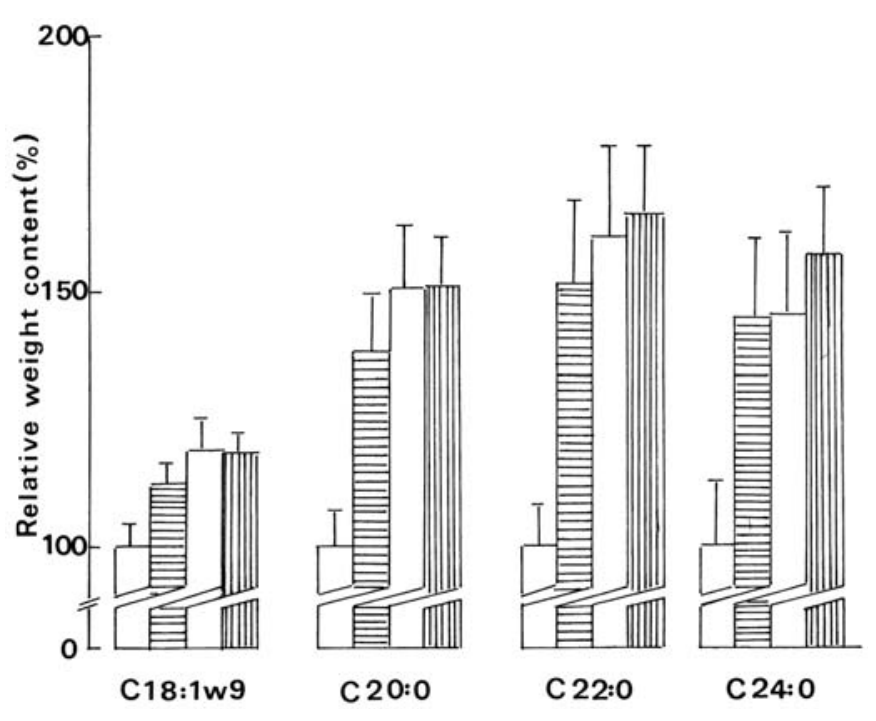

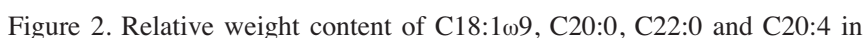
the brain phospholipids of control animals (left open columns) and $\omega 3 \mathrm{D}$ rats (horizontally hatched columns) examined 3 and 7 months after the start of the experiments, and of control animals (middle open columns) and $\omega 3 \mathrm{D}$ rats (vertically hatched columns) examined after exposure to the soybean and flaxseed oil-enriched diets (control animals) or to the flaxseed oilenriched diet $(\omega 3 \mathrm{D}$ rats). Mean values $( \pm \mathrm{SE})$ refer to 11-12 individual determinations, and are expressed relative to the mean value found in the control animals during the first 7 months of the present experiments. Such a reference value averaged $15.1 \pm 0.7 \%$ in the case of $\mathrm{C} 18: 1 \omega 9,0.29 \pm 0.02 \%$ in the case of $\mathrm{C} 20: 0,0.27 \pm 0.02 \%$ in the case of $\mathrm{C} 22: 0$ and $0.63 \pm 0.08 \%$ in the case of $\mathrm{C} 24: 0$ ( $n=17$ in all cases).

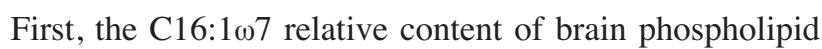
was comparable in control animals and $\omega 3 \mathrm{D}$ rats whether 3 months $(p>0.4)$ or 7 months $(p>0.5)$ after the onset of the present experiments. This contrasted with the higher value $(\mathrm{p}<0.001)$ found in second-generation $\omega 3 \mathrm{D}$ rats than in their corresponding control animals. The $\mathrm{C} 16: 1 \omega 7$ relative content failed to be significantly affected when the control animals were given access to either the soybean oil-enriched diet $(p>0.2)$ or flaxseed oil-enriched diet $(p>0.09)$. It was significantly higher $(\mathrm{p}<0.02)$, however, in the latter rats than in the former ones. It also failed to be significantly affected ( $p>0.5$ or more) when the $\omega 3 \mathrm{D}$ rats were exposed to the flaxseed oil-enriched diet.

C18:1 $\omega 9$ provided the first example of a fatty acid of which the relative content was higher $(\mathrm{p}<0.06)$ in $\omega 3 \mathrm{D}$ rats than in control animals both examined during the first 7 months of the present experiments whilst, in second-generation $\omega 3 \mathrm{D}$ rats, the mean $\mathrm{C} 18: 1 \omega 9$ relative content of brain phospholipids was lower, albeit not significantly so $(\mathrm{p}>0.5)$, than in the corresponding control animals (Fig. 2). Its relative content was higher $(\mathrm{p}<0.05)$ in the control animals exposed to an oil-enriched diet than in the control animals examined before such an exposure. It failed to differ significantly ( $p>0.2)$ in the $\omega 3 \mathrm{D}$ rats examined before and after exposure to the flaxseed oil-enriched diet, and in the control animals and $\omega 3 \mathrm{D}$ rats $(\mathrm{p}>0.5)$ both exposed to the flaxseed oil-enriched diet.

The C20:0 relative content of brain phospholipids was also significantly higher $(\mathrm{p}<0.01)$ in $\omega 3 \mathrm{D}$ rats than in control animals all examined during the first 7 months of the present experiments. Such a content failed to differ significantly $(p>0.3)$ in the $\omega 3 \mathrm{D}$ rats examined before $(3.96 \pm 0.32 \%$; $\mathrm{n}=12)$ and after $(4.32 \pm 0.28 \% ; \mathrm{n}=12)$ exposure to the flaxseed oil-enriched diet. The latter value was comparable $(p>0.6)$ to that recorded in the control rats also exposed to the flaxseed oil-enriched diet. It should be underlined, however, that the control rats exposed to either the soybean or flaxseed oilenriched diet displayed a higher $\mathrm{C} 20: 0$ relative content of brain phospholipids $(4.31 \pm 0.36 \%$; $n=12 ; \mathrm{p}<0.005)$ than the control rats examined during the first 7 months of the present experiments $(2.86 \pm 0.20 \%$; $\mathrm{n}=12)$. In the second-generation $\omega 3 \mathrm{D}$ rats, in mirror image of the $\omega 3 \mathrm{D}$ rats examined in this study, the C20:0 relative content of brain phospholipids was lower $(\mathrm{p}<0.05)$ than in the corresponding control animals.

The results concerning C22:0 were superimposable to those just described in the case of C20:0. Thus, the C22:0 relative content of brain phospholipids was significantly higher $(\mathrm{p}<0.02)$ in $\omega 3 \mathrm{D}$ rats than in control animals all examined during the first 7 months of the present experiments. Such a content failed to differ significantly $(\mathrm{p}>0.5)$ in the $\omega 3 \mathrm{D}$ rats examined before $(4.06 \pm 0.44 \%$; $n=12)$ and after $(4.42 \pm 0.49 \%$; $\mathrm{n}=12$ ) exposure to the flaxseed oil-enriched diet. The latter value was comparable $(\mathrm{p}>0.5)$ to that recorded in the control rats also exposed to the flaxseed oil-enriched diet. The control rats exposed to either the soybean or flaxseed oil-enriched diet displayed a higher $\mathrm{C} 22: 0$ relative content of brain phospholipids $(4.30 \pm 0.48 \% \circ \mathrm{n}=12 ; \mathrm{p}<0.01)$ than the control rats examined during the first 7 months of the present experiments $(2.68 \pm 0.22 \% ; n=11)$. All these features are indeed identical to those recorded in the case of C20:0. Moreover, in the second-generation $\omega 3 \mathrm{D}$ rats, the mean $\mathrm{C} 22: 0$ relative content of brain phospholipids again failed to be higher than in the corresponding control animals.

Last, the results recorded with C24:0 were again superimposable to those found in the case of C20:0 or C22:0. Thus, the $C$ 24:0 relative content of brain phospholipids was significantly higher $(\mathrm{p}<0.05)$ in $\omega 3 \mathrm{D}$ rats than in control animals all examined during the first 7 months of the present experiments. Such a content failed to differ significantly $(\mathrm{p}>0.5)$ in the $\omega 3 \mathrm{D}$ rats examined before $(9.16 \pm 1.00 \% ; \mathrm{n}=12)$ and after $(9.96 \pm 0.83 \% ; n=12)$ exposure to the flaxseed oilenriched diet. The latter value was comparable $(\mathrm{p}>0.7)$ to that recorded in the control rats also exposed to the flaxseed oilenriched diet. The control rats exposed to either the soybean or flaxseed oil-enriched diet displayed a higher $\mathrm{C} 24: 0$ relative content of brain phospholipids $(9.21 \pm 1.02 \%$; $\mathrm{n}=12 ; \mathrm{p}<0.05)$ than the control rats examined during the first 7 months of the present experiments $(6.33 \pm 0.84 \%$; $n=11)$. Moreover, in the second-generation $\omega 3 \mathrm{D}$ rats, the mean $\mathrm{C} 24: 0$ relative content of brain phospholipids was somewhat lower $(8.20 \pm 0.72 \%$; $\mathrm{n}=18)$, albeit not significantly so $(\mathrm{p}>0.2)$, than that found in the corresponding control animals $(9.49 \pm 0.79 \%$; $n=16)$.

Fig. 2 illustrates the analogy of results obtained in the

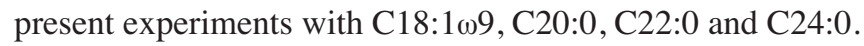

A further analogy between the 4 sets of results obtained with $\mathrm{C} 18: 1 \omega 9, \mathrm{C} 20: 0, \mathrm{C} 22: 0$ and $\mathrm{C} 24: 0$ consisted in the fact that, although failing to achieve statistical significance, the mean value for the relative content of these fatty acids in brain phospholipids was always higher in control rats exposed to the flaxseed oil-enriched diet than in the control rats exposed 


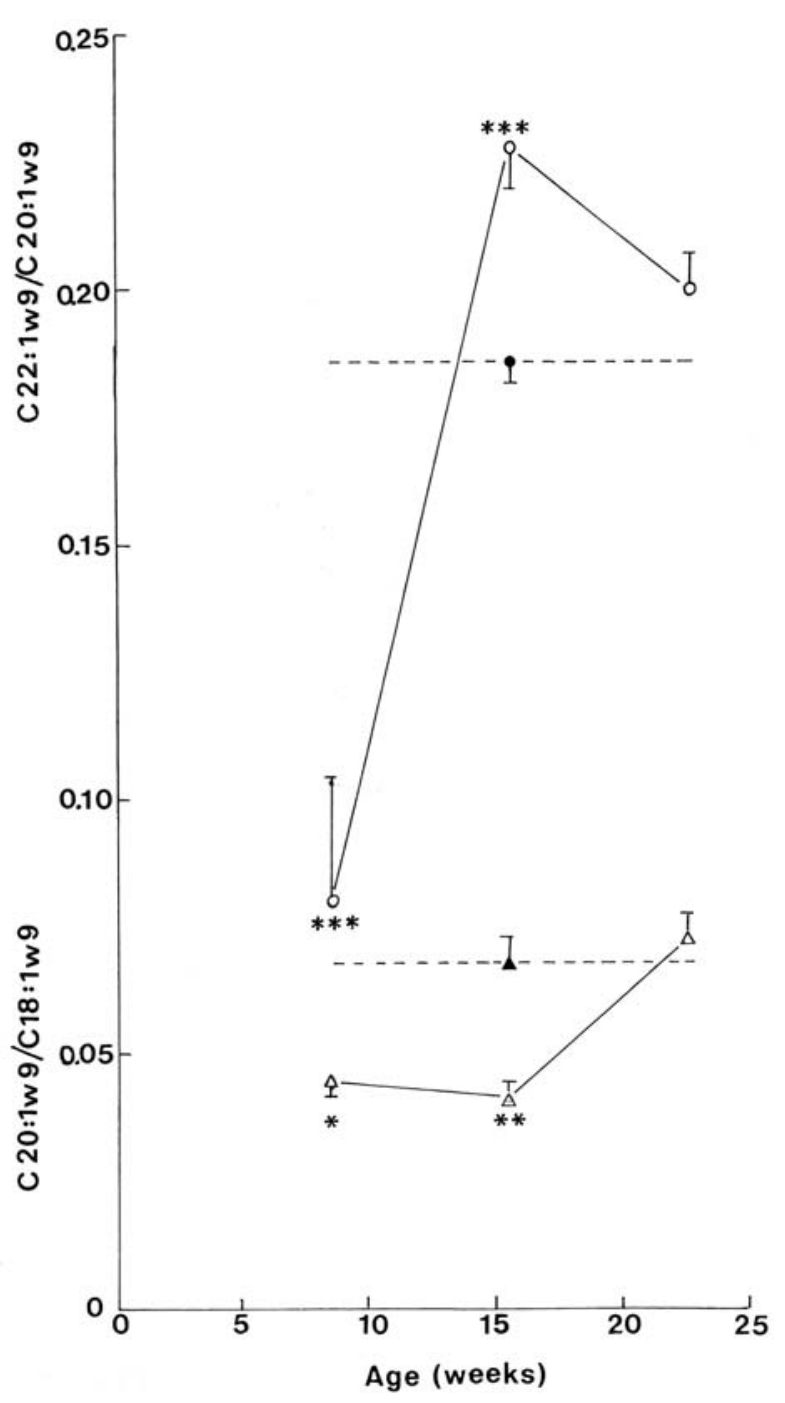

Figure 3. Age-related changes in the $\mathrm{C} 20: 1 \omega 9 / \mathrm{C} 18: 1 \omega 9$ (triangles) and C22:1 $109 / \mathrm{C} 20: 1 \omega 9$ (circles) ratio in the brain phospholipids of secondgeneration $\omega 3 \mathrm{D}$ rats (open symbols), as compared $\left({ }^{*} \mathrm{p}<0.01 ;{ }^{* *} \mathrm{p}<0.005\right.$; $\left.{ }_{* * *} \mathrm{p}<0.001\right)$ to control rats (closed symbols) of comparable mean age. Mean values $( \pm \mathrm{SE})$ refer to 6 second-generation $\omega 3$ rats at each age, and 16 control rats.

to the soybean oil-enriched diet. As a matter of fact, when all available data were pooled together, the relative abundance of these 4 fatty acids averaged in the former rats $123.0 \pm 6.6 \%$ $(\mathrm{n}=24 ; \mathrm{p}<0.025)$ of the corresponding mean values recorded in the latter rats $(100.0 \pm 7.2 \% ; n=24)$.

No significant difference in the $\mathrm{C} 16: 1 \omega 7 / \mathrm{C} 16: 0$ ratio was observed between control animals $(15.98 \pm 0.51 \%$; $n=11)$ and $\omega 3 \mathrm{D}$ rats $(15.90 \pm 0.44 \%$; $\mathrm{n}=12)$ examined during the first 7 months of the present experiments. Such was also the case ( $p>0.09$ ) when comparing second-generation $\omega 3 \mathrm{D}$ rats $(14.24 \pm 0.35 \%$; $n=18)$ to their control animals $(13.55 \pm 0.15 \%$; $\mathrm{n}=16$ ). In the control rats, the $\mathrm{C} 16: 1 \omega 7 / \mathrm{C} 16: 0$ also failed to be affected when they were exposed to the soybean oilenriched diet $(16.02 \pm 0.68 \%$; $n=6)$, whilst being increased $(\mathrm{p}<0.02)$ to $18.62 \pm 0.62 \%$ o $(n=6)$ when they were exposed to the flaxseed oil-enriched diet. Likewise, in the $\omega 3 \mathrm{D}$ rats exposed to the flaxseed oil-enriched diet, such a ratio progressively increased $(\mathrm{p}<0.06)$ from $15.76 \pm 0.81 \%$ o $(\mathrm{n}=6)$ before exposure to this diet to $16.67 \pm 1.04 \%(n=6)$ and $17.84 \pm 0.56 \%$ o $(n=6) 2$ and 4-5 weeks thereafter, respectively.

The C18:1 $\omega 9 / \mathrm{C} 18: 0$ ratio also failed to differ significantly $(\mathrm{p}>0.5)$ in control animals $(0.827 \pm 0.041 ; \mathrm{n}=11)$ and $\omega 3 \mathrm{D}$ rats $(0.860 \pm 0.032 ; n=12)$ examined during the first 7 months of the present experiments. Moreover, it failed to differ significantly in control rats given access during the last 4-5 weeks to either the soybean $(0.874 \pm 0.063 ; n=6)$ or flaxseed $(1.055 \pm 0.072 ; n=6)$ oil-enriched diet $(\mathrm{p}>0.09)$, in $\omega 3 \mathrm{D}$ rats examined before $(0.860 \pm 0.032 ; \mathrm{n}=12)$ or after $(0.936 \pm 0.033$; $\mathrm{n}=12$ ) exposure to the flaxseed oil-enriched diet ( $>>0.1)$, and in the control animals and $\omega 3 \mathrm{D}$ rats given access during the last 4-5 weeks to the flaxseed oil-enriched diet $(p>0.2)$. These findings contrast with the much lower C18:1w9/C18:0 ratio $(\mathrm{p}<0.001)$ found in the brain phospholipids of secondgeneration $\omega 3 \mathrm{D}$ rats $(0.699 \pm 0.024 ; \mathrm{n}=18)$, as compared to their control animals $(0.941 \pm 0.037 ; \mathrm{n}=16)$.

Last, the $(\mathrm{C} 18: 0+\mathrm{C} 18: 1 \omega 9) /(\mathrm{C} 16: 0+\mathrm{C} 16: 1 \omega 7)$ ratio again failed to differ significantly $(\mathrm{p}>0.2)$ in control animals $(1.51 \pm 0.05 ; \mathrm{n}=11)$ and $\omega 3 \mathrm{D}$ rats $(1.59 \pm 0.04 ; \mathrm{n}=12)$ examined during the first 7 months of the present experiments, this contrasting with the lower ratio $(\mathrm{p}<0.005)$ found in secondgeneration $\omega 3 \mathrm{D}$ rats $(1.47 \pm 0.04 ; \mathrm{n}=18)$ than in their control animals $(1.73 \pm 0.06 ; n=16)$. The same ratio failed to be affected in the control rats exposed to the soybean oil-enriched diet $(1.63 \pm 0.07 ; \mathrm{n}=6)$, whilst increasing $(\mathrm{p}<0.02)$ to $1.85 \pm 0.13$ $(n=6)$ in the control rats exposed to the flaxseed oil-enriched diet. In the $\omega 3 \mathrm{D}$ rats exposed for 2 and 4-5 weeks to the flaxseed oil-enriched diet, the mean values for such a ratio also progressively increased $(\mathrm{p}<0.06)$ from $1.56 \pm 0.07(\mathrm{n}=6)$ to $1.61 \pm 0.06(n=6)$ and $1.76 \pm 0.08(n=6)$ after 2 and $4-5$ weeks, respectively.

Precursors of nervonic acid. As recently reported in a study dealing with the content of liver phospholipids in C20:1 109

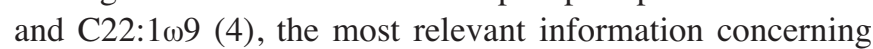
these precursors of nervonic acid in brain phospholipids was provided by the $\mathrm{C} 20: 1 \omega 9 / \mathrm{C} 18: 1 \omega 9$ and $\mathrm{C} 22: 1 \omega 9 / \mathrm{C} 20: 1 \omega 9$ ratios.

When compared to the results recorded at the same age in control rats, the $\mathrm{C} 20: 1 \omega 9 / \mathrm{C} 18: 1 \omega 9$ ratio was lower $(\mathrm{p}<0.03)$ after 7 months than after only 3 months of dietary $\omega 3$ deprivation, averaging in the former case $63.5 \pm 13.2 \%(\mathrm{df}=9)$ of the corresponding value found in the latter case $(100.0 \pm 9.0 \%$; $\mathrm{df}=10$ ). Likewise, in second-generation $\omega 3 \mathrm{D}$ rats, the $\mathrm{C} 20: 1 \omega 9 /$ $\mathrm{C} 18: 1 \omega 9$ ratio was lower $(\mathrm{p}<0.025)$ than in the corresponding control animals. As illustrated in Fig. 3, such a difference faded out, however, in the older second-generation $\omega 3 \mathrm{D}$ rats. In both the control and $\omega 3 \mathrm{D}$ rats, such a ratio increased when the animals were exposed to an oil-enriched diet. For instance, after 4-5 weeks of exposure to the flaxseed oil-enriched diet, the results averaged $125.4 \pm 7.4 \%(n=12 ; \mathrm{p}<0.05)$ of those recorded in the same type of rats before such an exposure $(100.0 \pm 9.5 \% ; n=11)$. In the $\omega 3 \mathrm{D}$ rats, the $\mathrm{C} 20: 1 \omega 9 / \mathrm{C} 18: 1 \omega 9$ indeed increased from $5.8 \pm 0.9 \%$ after 7 months of $\omega 3$ deprivation to $7.0 \pm 0.7 \%$ and $7.4 \pm 0.5 \%$ ( $n=6$ in all cases) after 2 and 4-5 weeks of exposure to the flaxseed oil-enriched diet, respectively. 


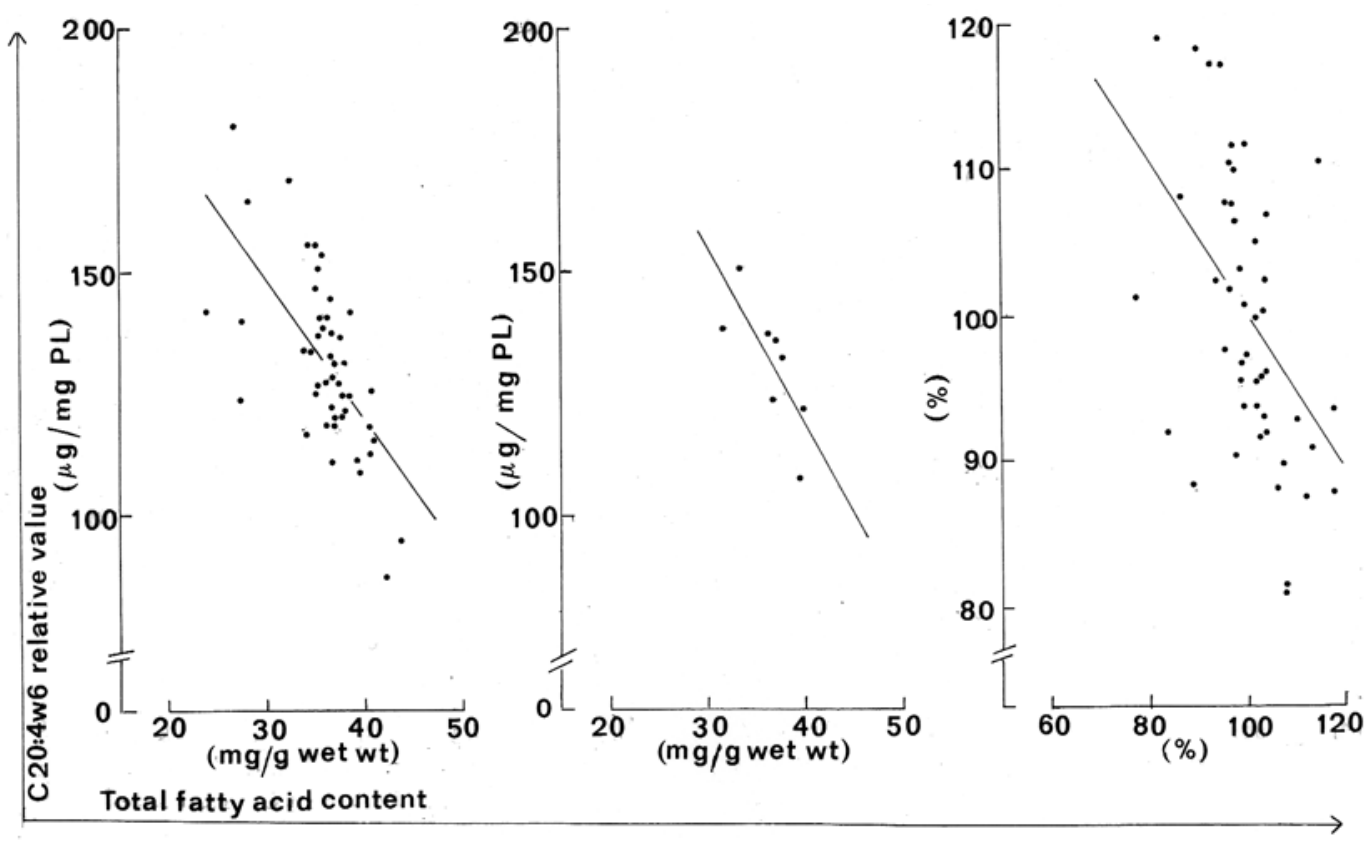

Figure 4. Correlation between the absolute values for the C20:4 6 relative content of brain phospholipids and total fatty acid content of such phospholipids in the 47 animals examined in this study (left), between the mean absolute values for these variables in the 8 groups of rats considered in this work (middle), and between the individual values found in the 47 animals and expressed relative to the corresponding mean values recorded in each group of rats (right).

Likewise, after 3 and 7 months of $\omega 3$ deprivation, respectively, the $\mathrm{C} 22: 1 \omega 9 / \mathrm{C} 20: 1 \omega 9$ ratio in brain phospholipids averaged $88.8 \pm 6.4 \%(\mathrm{df}=10 ; \mathrm{p}<0.11)$ and $80.4 \pm 8.2 \%(\mathrm{df}=9$; $\mathrm{p}<0.05$ ) of the mean corresponding values found in control rats of the same age. In the youngest second-generation $\omega 3 \mathrm{D}$ rats, such a ratio was also lower than in control rats, such a difference being once again no more observed in older secondgeneration $\omega 3 \mathrm{D}$ rats (Fig. 3). In the control rats, the C22:1 109 / $\mathrm{C} 20: 1 \omega 9$ ratio in brain phospholipids was higher $(\mathrm{p}<0.005)$ after 4-5 weeks of exposure to the flaxseed oil-enriched diet, as compared to soybean oil-enriched diet. In the $\omega 3 \mathrm{D}$ rats also exposed for 4-5 weeks to the flaxseed oil-enriched diet, such a ratio reached a value even higher $(\mathrm{p}<0.05)$ than that recorded in the control rats after the same length of exposure to the flaxseed oil-enriched diet.

Coordinated changes in selected phospholipid variables. A cause-to-effect link between changes in the $\omega 3$ fatty acid content of brain phospholipids and subsequent changes in other brain lipid variables was supported by the close-tosignificant correlation $(\mathrm{p}<0.06)$ found between the $\mathrm{C} 22: 6 \mathrm{w3}$ and $C 20: 4 \omega 6$ relative weight content of brain phospholipids in the 47 rats examined in this study.

Considering that, in the second-generation $\omega 3 \mathrm{D}$ rats, two major perturbations of brain phospholipids consisted in their decreased total fatty acid content and increased C20:4w6 relative content, an attempt was made to investigate whether these two variables underwent coordinated changes under the present experimental conditions, when comparing either distinct group of rats or individual animals within each of such groups. As illustrated in Fig. 4 (left panel), there was a highly significant negative correlation $(\mathrm{r}=-0.6393 ; \mathrm{df}=45$; $\mathrm{p}<0.001$ ) between the individual values for these two variables, when considering all animals examined in the present study. However, there was also a significant negative correlation $(\mathrm{r}=-0.7922 ; \mathrm{df}=6 ; \mathrm{p}<0.05)$ between the same two variables, when considering only the mean values recorded in each of the 8 groups of rats investigated in our recent experiments (Fig. 4, middle panel). Hence, in order to assess the possible existence of individual correlation, independently of any group affect, the coefficient of correlation between the individual values for each variable was first calculated in each of the 8 groups of rats. It averaged $-0.5529 \pm 0.1222(\mathrm{n}=8)$, a value significantly different from zero $(\mathrm{p}<0.005)$. The mean values found for the two variables under consideration within each group of rats was then taken, in all cases, as the $100 \%$ reference values. Covariance analysis allowed to pool together the data so obtained in each group of rats. This last approach, illustrated in Fig. 4 (right panel), yielded again a significant negative correlation between the total fatty acid content of brain phospholipids and their $\mathrm{C} 20: 4 \omega 6$ relative weight content $(\mathrm{r}=-0.4801 ; \mathrm{df}=31 ; \mathrm{p}<0.01)$. This indicates that, independently of any group effect, individual values for these two lipid variables indeed display coordinated variation.

Such a situation is not unique. Considering that C24:0 represents the most abundant fatty acid among the 3 saturated fatty acids (C20:0, C22:0 and C24:0) displaying virtually identical variations in the 8 groups of rats here under examination, the weight percentage of C24:0 and that of C20:4 6 were also compared, after expressing all individual values relative to the mean corresponding value found within the same group of rat, i.e. using an analytical procedure similar to that illustrated in Fig. 4 (right panel). Under these conditions, a highly significant negative correlation $(\mathrm{r}=$ $-0.7520 ; \mathrm{df}=45 ; \mathrm{p}<0.001)$ was again observed between the two phospholipid variables under consideration. Likewise, 
always using the same analytical procedure, there was also a highly significant negative correlation $(r=-0.8275 ; \mathrm{df}=45$; $\mathrm{p}<0.001)$ between the $\mathrm{C} 18: 1 \omega 9$ and $\mathrm{C} 20: 4 \omega 6$ relative content of brain phospholipids. The correlation coefficient was not always negative. For instance, using the same analytical procedure, a highly significant positive correlation $(\mathrm{r}=$ $+0.7671 ; \mathrm{df}=45 ; \mathrm{p}<0.001)$ was observed between the $\mathrm{C} 16: 0$ and $\mathrm{C} 20: 4 \omega 6$ relative content of brain phospholipids. It should again be stressed that such a correlation between individual values for the two variables prevailed independently of any group effect. In our opinion, such a correlation was even more remarkable in that the coefficient of variation (SD/mean) for the $\mathrm{C} 16: 0$ relative content of brain phospholipids, expressed relative to the mean value recorded in the same group of rats, did not exceed $4.93 \%(n=47)$, with extreme individual values of 90.3 and $109.5 \%$. In other words, the observed correlation prevailed within a quite narrow range of individual variations. Incidentally, even the absolute values for the $\mathrm{C} 16: 0$ relative content of brain phospholipids ranged between the extreme individual values of 18.5 and $25.6 \%$, with a coefficient of variation of no more than $6.35 \%(n=47)$.

\section{Discussion}

The present findings indicate that the changes in brain phospholipid variables caused by dietary $\omega 3$-deprivation often represented a progressive and relatively slow process. Such was the case for the decrease in the total content of fatty acids in such phospholipids, as illustrated in Fig. 1. Likewise, for the 3 variables listed in Table I and relative to long-chain polyunsaturated $\omega 3$ fatty acids, the results recorded after 3 and 7 months of dietary $\omega 3$ deprivation, when expressed relative to the mean corresponding values recorded at the same age in the control animals, indicate a further decrease by $19.6 \pm 2.8 \%$ $(\mathrm{df}=30 ; \mathrm{p}<0.001)$ over a period of 4 months. The difference between the rats deprived of dietary $\omega 3$ fatty acids for either 3 or 7 months indeed consisted in the further decrease of the phospholipid C22:5 $33(\mathrm{p}<0.005)$ and $\mathrm{C} 22: 6 \omega 3(\mathrm{p}<0.005)$ content. The changes in the relative contribution of $\mathrm{C} 20: 4 \omega 6$ and $\mathrm{C} 22: 4 \omega 6$ to brain phospholipids provide another example of such a progressive process (Fig. 1) with more pronounced differences between control and $\omega 3 \mathrm{D}$ rats after 7 months than after only 3 months of $\omega 3$ deprivation. When the $\omega 3 \mathrm{D}$ rats were exposed to the flaxseed oil-enriched diet, the normalization of brain phospholipid variables, when observed, appeared, however, as a more rapid process, completed within 4-5 weeks.

The present results are in fair agreement with those collected by Igarashi et al $(5,6)$ in male rats exposed to an $\omega 3$-deficient diet for 15 weeks after weaning. The changes in the brain phospholipid C22:5 $33, \mathrm{C} 22: 6 \omega 3, \mathrm{C} 18: 2 \omega 6, \mathrm{C} 20: 4 \omega 6$ and $\mathrm{C} 22: 5 \omega 6$ relative content were indeed comparable in both cases. An increase in the total relative content of long-chain polyunsaturated $\omega 6$ fatty acids in the brain phospholipids of $\omega 3$-depleted rats was also recorded in both studies, from about 9.9 to $16.5 \%$ in the prior study and from $16.8 \pm 0.4 \%$ $(n=11)$ to $21.9 \pm 0.6 \%(n=12 ; p<0.001)$ in the present one. However, the total content of monodesaturated fatty acids in brain phospholipids was slightly decreased in the prior study, whilst increasing from a control value of $16.5 \pm 0.8 \%(n=11)$ to $18.6 \pm 0.7 \%(\mathrm{n}=12 ; \mathrm{p}<0.07)$ in the present work.
The situation found in the rats deprived of a dietary supply of long-chain polyunsaturated $\omega 3$ fatty acids for 3 to 7 months both resemble that otherwise prevailing in second-generation $\omega 3 \mathrm{D}$ rats and differ from it in several respects, as documented by the following examples.

A first analogy between the two types of $\omega 3 \mathrm{D}$ rats consisted in the decrease of the total fatty acid content of brain phospholipids, contrasting with an unchanged total fatty acid content of brain triglycerides.

In the case of the long-chain polyunsaturated $\omega 3$ fatty acids, both animal models of dietary $\omega 3$ deprivation resulted in a depletion of these $\omega 3$ fatty acids in brain phospholipids, with apparent impairment of $\mathrm{C} 22: 6 \omega 3$ conversion to $\mathrm{C} 22: 5 \omega 3$. The most unexpected difference between these two models, however, consisted in the lower $\mathrm{C} 22: 5 \mathrm{\omega} 3$ content of brain phospholipids in the $\omega 3 \mathrm{D}$ rats deprived of a dietary supply of $\omega 3$ fatty acids for only 7 months than in the secondgeneration $\omega 3 \mathrm{D}$ rats.

In the case of the long-chain polyunsaturated $\omega 6$ fatty acids, the similarity between the two models included the increase in the $\mathrm{C} 20: 3 \omega 6, \mathrm{C} 20: 4 \omega 6$ and $\mathrm{C} 22: 4 \omega 6$ relative weight content of brain phospholipids, the lowering of the C20:3 $166 /$ $\mathrm{C} 18: 2 \omega 6$ ratio, and the increase in the $\mathrm{C} 20: 4 \omega 6 / \mathrm{C} 20: 3 \omega 6$ ratio. As a matter of fact, if attention is restricted to statistically significant differences between control animals and $\omega 3 \mathrm{D}$ rats, none of the variables concerning the $\omega 6$ fatty acids were affected in a different manner in the two animal models of $\omega 3$ deprivation.

Such was not the case, however, in terms of the saturated and monodesaturated fatty acids. Qualified analogies between the two models were found in the case of C16:0, C18:0, and

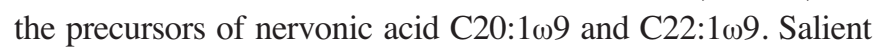
differences between the two models, i.e. with statistically significant differences between $\omega 3 \mathrm{D}$ rats and control rats of opposite directions in the two models, were not common, being restricted to the $\mathrm{C} 20: 0$ relative weight content which was increased in the $\omega 3 \mathrm{D}$ rats examined during the first 7 months of the present experiments, whilst being decreased in the second-generation $\omega 3 \mathrm{D}$ rats. Nevertheless, if attention is paid to the four fatty acids considered in Fig. 2, the obvious increase of their relative content in the brain phospholipids of $\omega 3 \mathrm{D}$ rats deprived of a dietary supply of $\omega 3$ fatty acids for 3 to 7 months contrasts with the fact that the mean values for the same fatty acids were always lower, albeit not significantly so, in the second-generation $\omega 3 \mathrm{D}$ rats than in the corresponding control animals. As a matter of fact, when pooling together all available data, the relative weight content of these four fatty acids in the brain phospholipids of secondgeneration $\omega 3 \mathrm{D}$ rats only represented $88.4 \pm 3.1 \% \quad(n=72$; $\mathrm{p}<0.025$ ) of the mean corresponding values found in the control animals $(100.0 \pm 4.0 \% ; \mathrm{n}=64)$.

At this point, it should be emphasized that the female control animals and $\omega 3 \mathrm{D}$ rats examined 3 and 7 months after the onset of the present experiments were about 20 to 38 weeks old, as compared to the female second-generation rats the age of which ranged between the extreme values of 8-9 and 22-23 weeks. This information should not be ignored since, in both control animals and $\omega 3 \mathrm{D}$ rats (even the second-generation $\omega 3 \mathrm{D}$ rats), age-related changes in the brain phospholipid fatty 
acid pattern may take place. This is illustrated, for instance, in Fig. 3, which refers to second-generation $\omega 3 \mathrm{D}$ rats. Likewise, in the control rats examined in the present experiments, and to cite only one example, the $\mathrm{C} 16: 0 / \mathrm{C} 14: 0$ ratio in brain phospholipids decreased $(\mathrm{p}<0.001)$ between the 20th and 38th week of life, from $302.1 \pm 17.1$ to $173.1 \pm 22.8$ ( $n=5-6$ ).

With this reservation in mind, the above-mentioned differences between the $\omega 3 \mathrm{D}$ rats examined in the present experiments and the second-generation $\omega 3 \mathrm{D}$ rats investigated in a prior study lead us to suggest that the present experimental design could be more relevant to the situation prevailing in human subjects also affected by an insufficient dietary supply of long-chain polyunsaturated $\omega 3$ fatty acids.

In this respect, the present work provides strong support to the view that the several differences in the brain phospholipid fatty acid total content and pattern found in $\omega 3 \mathrm{D}$ rats, as compared to control animals, represents the outcome of a tightly coordinated sequence of events initiated by the insufficient dietary supply of long-chain polyunsaturated $\omega 3$ fatty acids.

As already mentioned in the introduction of this report, the second major issue investigated in this study refers to the identification of those factors possibly responsible for the postulated increase in food intake occurring when the $\omega 3 \mathrm{D}$ rats are given access to the flaxseed oil-enriched diet (2). Such a postulated increase in food intake could involve flaxseed dietary self-selection in the $\omega 3$-depleted rats (7). It could also be attributable to the orexigenic effects of exogenously provided $\omega 3$ fatty acids (8-11). If so, the present results could indicate that $\mathrm{C} 22: 5 \omega 3$, rather than $\mathrm{C} 22: 6 \omega 3$, plays a key role in this respect. In turn, the comparison with the results obtained in second-generation $\omega 3 \mathrm{D}$ rats would then suggest that the higher body weight found in the latter rats, but not so in the 7-week-old rats exposed for 3 to 7 months to an $\omega 3$-depleted diet, may not be related to a primary change in the fatty acid pattern of brain phospholipids. None of the changes evoked by exposure of the latter rats to the flaxseed oil-enriched diet, e.g. the lowering of the phospholipid content in C20:4w6 and C22:4 6 , duplicated the difference otherwise found when comparing second-generation $\omega 3 \mathrm{D}$ rats to control animals. The proposal that the increased body weight of second-generation $\omega 3 \mathrm{D}$ rats may represent an early metabolic event not tightly related to a primary alteration of brain phospholipids is also supported by the finding that it fades out later in life, despite the persistence of a severe perturbation of brain phospholipid fatty acid profile $(1,12)$.

In conclusion, the present data document the suitability of a dietary deprivation of $\omega 3$ fatty acids for 3 or more months as an animal model to assess the remodelling of brain phospholipids resulting from such a deprivation. The present results also point to an increase in the $\mathrm{C} 22: 5 \mathrm{w} 3$ content of brain phospholipids as a key determinant of the orexigenic effects of exogenous $\omega 3$ fatty acids, when supplied to $\omega 3 \mathrm{D}$ rats.

\section{Acknowledgments}

This study was supported by a grant from the Belgian Foundation for Scientific Medical Research (3.4574.07), and by Convention 5459 (Project WALNUT-20) from the Région Wallonne (Namur, Belgium). We are grateful to A. Chwalick and A. Dufour for technical assistance, and C. Demesmaeker for secretarial help.

\section{References}

1. Malaisse WJ, Portois L, Sener A and Carpentier YA: Brain phospholipid and triglyceride fatty acid content and pattern in rats depleted in long-chain polyunsaturated $\omega 3$ fatty acids. Trends Cell Mol Biol 2: 69-76, 2007.

2. Sener A, Zhang Y, Bulur N, Louchami K, Malaisse WJ and Carpentier YA: The metabolic syndrome of $\omega 3$-depleted rats. II. Body weight, adipose tissue mass and glycemic homeostasis. Int J Mol Med 24: 125-129, 2009.

3. Malaisse WJ, Bulur N, Zhang Y, Hacquebard M, Portois L, Sener A and Carpentier YA: The metabolic syndrome of $\omega 3$ depleted rats. I. Liver data. Int J Mol Med 24: 111-123, 2009.

4. Malaisse WJ, Zhang Y, Portois L, Sener A and Carpentier YA: Liver phospholipid and triglyceride content of 11-eicosenoic and 13-docosenoic acids: gender difference and perturbation in type 1 and type 2 diabetic rats. Met Funct Res Diab 1: 17-22, 2008.

5. Igarashi M, DeMar JC, Ma K, Chang L, Bell JM and Rapoport SI: Docosahexaenoic acid synthesis from $\alpha$-linolenic acid by rat brain is unaffected by dietary n-3 PUFA deprivation. J Lipid Res 48: 1150-1158, 2007.

6. Igarashi M, Ma K, Chang L, Bell JM and Rapoport SI: Dietary n-3 PUFA deprivation for 15 weeks upregulates elongase and desaturase expression in rat liver but not brain. J Lipid Res 48: 2463-2470, 2007.

7. Dunlap S and Heinrichs SC: Neuronal depletion of omega-3 fatty acids induces flax seed dietary self-selection in the rat. Brain Res 1250: 113-119, 2009.

8. Barber MD, Ross JA, Voss AC, Tisdale MJ and Fearon KC: The effect of an oral nutritional supplement enriched with fish oil on weight-loss in patients with pancreatic cancer. Br J Cancer 81: 80-86, 1999.

9. Brown TT, Zelnik DL and Dobs AS: Fish oil supplementation in the treatment of cachexia in pancreatic cancer patients. Int J Gastrointest Cancer 34: 143-150, 2003.

10. Goncalves CG, Ramos EJ, Romanova IV, Suzuki S, Chen C and Meguid MM: Omega-3 fatty acids improve appetite in cancer anorexia, but tumor resecting restores it. Surgery 139: 202-208, 2006.

11. Ramos EJ, Romanova IV, Suzuki S, Chen C, Ugrumov MV, Sato T, Goncalves CG and Meguid MM: Effects of omega-3 fatty acids on orexigenic and anorexigenic modulators at the onset of anorexia. Brain Res 1046: 157-164, 2005.

12. Oguzhan B, Sancho V, Acitores A, Villanueva-Peñacarrillo M-L, Portois L, Chardigny J-M, Sener A, Carpentier YA and Malaisse WJ: Alteration of adipocyte metabolism in $\omega 3$ fatty acid-depleted rats. Horm Metab Res 38: 789-798, 2006. 